\title{
Single Channel Testing for Characterization of the Direct Gas Cooled Reactor and the SAFE-100 Heat Exchanger
}

\author{
S.M. Bragg-Sitton ${ }^{1,3}$, R. Kapernick ${ }^{2}$, T.J. Godfroy ${ }^{3}$ \\ ${ }^{1}$ Department of Nuclear Engineering and Radiological Sciences, University of Michigan, Ann Arbor, MI 48109 \\ ${ }^{2}$ Los Alamos National Laboratory, Los Alamos, NM 87545 \\ ${ }^{3}$ Propulsion Research Center, NASA Marshall Space Flight Center, Huntsville, AL 35812 \\ (256)544-6272, Shannon.Bragg-Sitton@msfc.nasa.gov
}

\begin{abstract}
Experiments have been designed to characterize the coolant gas flow in two space reactor concepts that are currently under investigation by NASA Marshall Space Flight Center and Los Alamos National Laboratory: the directdrive gas-cooled reactor (DDG) and the SAFE-100 heatpipe-cooled reactor (HPR). For the DDG concept, initial tests have been completed to measure pressure drop versus flow rate for a prototypic core flow channel, with gas exiting to atmospheric pressure conditions. The experimental results of the completed DDG tests presented in this paper validate the predicted results to within a reasonable margin of error. These tests have resulted in a re-design of the flow annulus to reduce the pressure drop. Subsequent tests will be conducted with the re-designed flow channel and with the outlet pressure held at $150 \mathrm{psi}(1 \mathrm{MPa})$. Design of a similar test for a nominal flow channel in the HPR heat exchanger (HPRHX) has been completed and hardware is currently being assembled for testing this channel at 150 psi. When completed, these test programs will provide the data necessary to validate calculated flow performance for these reactor concepts (pressure drop and film temperature rise).
\end{abstract}

\section{INTRODUCTION}

At present, several near-term space fission systems have been proposed for outer planetary missions. Two of these concepts are considered in the present work: the Direct Drive Gas-Cooled Reactor (DDG) (Wright and Lipinski, 2003) and the SAFE-100 heatpipe-cooled reactor (HPR), (VanDyke, 2002). Both concepts are fast-spectrum reactors that utilize highly enriched $\mathrm{UN}$ fuel, but differ in the mechanism of heat removal from the reactor. In the DDG design the coolant passes through annular channels in the core, whereas in the HPR, the heatpipes extend out from the core and are connected to heat exchangers, which transfer the heat from the heatpipes to the coolant. Both concepts utilize a closed Brayton cycle for the power conversion system, whose operating efficiency is sensitive to the system pressure drop.

Because the DDG can directly drive the Brayton turbo machinery without requiring an intermediate heat exchanger, it is possible to configure the system such that there are no external surfaces or pressure boundaries that are refractory metal even though the gas delivered to the turbine is $1144 \mathrm{~K}$. The $\mathrm{He} / \mathrm{Xe}$ gas mixture is a good heat transport medium when flowing, and a good insulator when stagnant. Judicious use of stagnant cavities as insulating regions allows transport of the 1144-K gas while keeping all external surfaces below $900 \mathrm{~K}$ (Godfroy et al., 2003). The DDG system is also relatively simple in its design: no additional coolant pumps, heat exchangers, or freeze-thaw systems are required.

The HPR is a 100 kilowatt thermal heat pipe concept which passively extracts the heat from fission via liquid metal heat pipes to heat exchangers (VanDyke, 2002). Two or three heat exchangers are proposed, each connected to a completely independent power conversion system, which eliminates the risk of a single-point failure and thus provides high reliability.

For both concepts, a two-step experimental approach has been adopted, with the first step being tests of highlyinstrumented single channels. The follow-on tests will consist of prototypic, full-scale partial arrays of the core and heat exchanger (HPR only). The test article for the HPR will comprise 19 modules vs. 61 modules in the SAFE-100 
reactor, and only one heat exchanger (Kapernick and Guffee, 2003 discusses the required test conditions and reasons for using only one heat exchanger). The test article for the DDG will comprise a 37 -channel core array vs. 85 channels in the actual core.

The single channel tests will provide data on the channel flow performance (pressure drop and film temperature rise). The partial-array tests will serve to provide pressure drop and flow distribution data for the reactor (DDG) and heat exchanger (HPR) systems. These tests will also provide operational data (e.g. startup and shutdown) and will demonstrate the robustness for the systems when operated at prototypic conditions (Kapernick and Guffee, 2003).

\section{EXPERIMENT DESIGN: DIRECT-DRIVE GAS COOLED REACTOR}

The experimental model of the single flow channel through the DDG reactor core was designed for simplified, low cost testing of the flow performance in the DDG system. Testing of a single channel allows for increased instrumentation relative to what is possible in the multi-channel test article for follow-on testing, due to the simplified access to the flow annulus. These tests provide the detailed flow performance information and allow assessment of the design and of potential design improvements prior to construction of the multi-channel test articles. To simulate the heat that would be produced by nuclear fission, shaped graphite heaters are used to approximate the power profile that would be present in an actual fueled reactor. The DDG reactor system is designed to use a gas coolant that is a 70/30 (atom percent) mixture of $\mathrm{He} / \mathrm{Xe}$. For the initial, single-channel tests, nitrogen gas was used as the working fluid instead of $\mathrm{He} / \mathrm{Xe}$ for simplicity and reduced cost. For the multi-channel tests a $20 \% \mathrm{He} / 80 \% \mathrm{Ar}$ mixture is proposed to be used, which provides reasonable similarity to the $\mathrm{He} / \mathrm{Xe}$ gas mixture for Reynolds numbers, dynamic heads and Mach numbers. The test matrix was selected to span a range of Reynolds number from laminar to well into turbulent flow. The Reynolds number, $R e$, can be calculated from Eq. (1) using the hydraulic diameter of the flow channel, $D_{h}$, the radially averaged flow velocity, $u_{\text {avg }}$, and the kinematic viscosity, $v$. (Note: All parameters are defined in the Nomenclature section at the end of this paper.)

$$
\operatorname{Re}=\frac{u_{a v g} D_{h}}{v}
$$

Pressure drop was calculated using a standard expression for pressure drop, neglecting buoyancy (Kays and London, 1964):

$$
\Delta P_{s}=\frac{\dot{m}^{2}}{2 g_{c} \rho_{\text {in }} A^{2}}\left(\left(K_{c}+1-\sigma^{2}\right)+2\left(\frac{\rho_{\text {in }}}{\rho_{\text {out }}}-1\right)+\frac{4 f L}{D_{h}} \frac{2 \rho_{\text {in }}}{\rho_{\text {in }}+\rho_{\text {out }}}+\left(K_{e}-1+\sigma^{2}\right)\right),
$$

where for turbulent flow a smooth tube correlation was used for the friction factor (Kays and London, 1964):

$$
f=0.079 \mathrm{Re}^{-0.25} .
$$

To simplify and expedite the single channel experiments, initial testing was not conducted at the actual temperature and pressure that will be seen in the full core demonstrator. Instead, nitrogen gas entered the channel at approximately room temperature and exited the channel at ambient pressure. Power was applied to the resistance heater, located inside the fuel tube, with a goal of matching the axial temperature rise expected for the reactor core; prototypic outlet temperature for the 37-pin DDG will be approximately $850 \mathrm{~K}\left(577^{\circ} \mathrm{C}\right)$. The temperature rise in the channel was measured by type $\mathrm{K}$ thermocouples placed at the inlet and outlet of the flow channel.

These tests served to provide useful initial data, but the higher Reynolds number cases were subject to compressible flow effects through the orifice, which were not accounted for in the analysis. Follow-on tests will be conducted with an outlet pressure of 150 psi to eliminate these effects.

A sample test matrix, corresponding to the spiral wrap annulus design with a triangular orifice, is provided in Table 1. Note that the $\Delta \mathrm{T}$ shown in the table reflects the average radial temperature difference between the coolant and the wall temperature on the inner edge of the flow channel. This matrix was designed to study the flow characteristics 
in the annulus over a range of Reynolds numbers, from laminar $(\operatorname{Re} \sim 1500)$ to turbulent $(\operatorname{Re} \sim 15000)$. In these tests the axial coolant temperature rise is held constant while the heater power and coolant flow rate are varied to achieve a desired Reynolds number for the flow. Inlet temperature is approximately constant at room temperature, $295 \mathrm{~K}$ $\left(22{ }^{\circ} \mathrm{C}\right)$, requiring an outlet temperature of approximately $475 \mathrm{~K}\left(202{ }^{\circ} \mathrm{C}\right)$ to achieve a temperature rise within the desired range.

TABLE 1. Sample Test Matrix for Testing of a Single Channel in the DDG Reactor Core.

\begin{tabular}{|c|c|c|c|c|c|c|c|}
\hline Case & $\begin{array}{c}\text { Reynolds } \\
\text { Number }\end{array}$ & $\begin{array}{c}\text { Power } \\
(\mathrm{kW})\end{array}$ & $\begin{array}{c}\text { Mass Flow Rate } \\
(\mathrm{g} / \mathrm{s})\end{array}$ & $\begin{array}{c}\Delta \mathrm{P}_{\text {axial }} \\
(\mathrm{kPa})\end{array}$ & $\begin{array}{c}\Delta \mathrm{T}_{\text {radial }} \\
(\mathrm{K})\end{array}$ & $\begin{array}{c}\text { Mach No. } \\
\text { Exit }\end{array}$ & $\begin{array}{c}\text { Mach No. } \\
\text { Orifice }\end{array}$ \\
\hline 1 & 1500 & 0.147 & 0.788 & 1.8 & 117.5 & 0.038 & 0.072 \\
2 & 2000 & 0.196 & 1.05 & 3.0 & 152.6 & 0.050 & 0.097 \\
3 & 2500 & 0.246 & 1.31 & 4.4 & 150.0 & 0.063 & 0.121 \\
4 & 3000 & 0.295 & 1.58 & 6.2 & 140.2 & 0.074 & 0.145 \\
5 & 3500 & 0.344 & 1.84 & 8.2 & 136.1 & 0.086 & 0.169 \\
6 & 4000 & 0.393 & 2.10 & 10.4 & 134.0 & 0.097 & 0.193 \\
7 & 4500 & 0.442 & 2.36 & 12.8 & 133.2 & 0.108 & 0.217 \\
8 & 5000 & 0.491 & 2.63 & 15.4 & 132.7 & 0.118 & 0.242 \\
9 & 6000 & 0.589 & 3.15 & 21.0 & 133.0 & 0.138 & 0.290 \\
10 & 7000 & 0.688 & 3.68 & 27.1 & 135.2 & 0.155 & 0.338 \\
11 & 8000 & 0.786 & 4.20 & 33.7 & 138.8 & 0.171 & 0.386 \\
12 & 9000 & 0.884 & 4.73 & 40.6 & 142.1 & 0.186 & 0.435 \\
13 & 10000 & 0.982 & 5.25 & 47.7 & 145.2 & 0.200 & 0.483 \\
14 & 11000 & 1.081 & 5.78 & 55.0 & 148.0 & 0.212 & 0.531 \\
15 & 12000 & 1.179 & 6.30 & 62.5 & 150.6 & 0.223 & 0.580 \\
16 & 13000 & 1.277 & 6.83 & 70.1 & 153.0 & 0.233 & 0.628 \\
17 & 14000 & 1.375 & 7.35 & 77.9 & 155.3 & 0.242 & 0.676 \\
18 & 15000 & 1.473 & 7.88 & 85.7 & 157.4 & 0.251 & 0.725 \\
\hline
\end{tabular}

\section{EXPERIMENT DESIGN: SAFE-100 HEAT EXCHANGER (HPR-HE)}

Due to the similarity in the configuration of the coolant flow channels in the HPR-HX and the flow channels in the DDG, it is possible to test a nominal heat exchanger flow channel with only minor modifications to the test stand. In the HPR-HX, the size of the coolant annulus also varies with radial position across the core to maintain adequate cooling radially across the bank of heat pipes emerging from the reactor core. For testing purposes, only the central flow channel was constructed. In the actual HX, the length of the flow channel is only 8 " $(20.3 \mathrm{~mm})$. To take advantage of existing resistance heater hardware, the designed test article is 17" $(432 \mathrm{~mm})$ in length, and the desired flow conditions will be achieved over an 8 " region along the test article. The HX test will employ constant diameter heaters.

A test matrix has been calculated in the same fashion as for the DDG tests, with the goal being to determine the pressure drop along the channel length over the same range of Reynolds numbers that were studied in the DDG tests $(\mathrm{Re}=1500-15000)$, maintaining a specified temperature rise along the channel with varying power and flow rate. At the time this paper was submitted, hardware and diagnostics were being assembled to conduct the full range of tests at $150 \mathrm{psi}(1.0 \mathrm{MPa})$ outlet pressure. The measured temperature and pressure profiles will be used to determine constants in the thermal hydraulic empirical correlations for the friction factor and Nusselt number in the flow channel. As discussed in Takase (2000), the friction factor, $f$, for an annular flow channel roughened by square ribs is given by:

$$
f=C 1 \cdot(\operatorname{Re})^{C 2}\left(\frac{T k_{w}}{T k_{b}}\right)^{-0.5}
$$


where $T k_{w}$ and $T k_{b}$ are the wall and bulk temperatures, respectively, expressed in degrees $\mathrm{K}$. The coefficient $C 1$ and the exponent $C 2$ will be determined empirically from the experimental data. Under fully developed flow conditions, Takase (2000) also provides a general expression for the relationship between the Nusselt $(\mathrm{Nu})$ number and the Reynolds number for a square-ribbed annulus:

$$
N u=C 3 \cdot(\operatorname{Re})^{C 4} \operatorname{Pr}^{0.4},
$$

where Pr is the Prandtl number. The Nusselt number is related to the heat transfer coefficient $h$ by $N u=h * D_{h} / k$, where $k$ is the conductivity. Again, the constants $C 3$ and $C 4$ will be determined empirically from the experimental data. As in the DDG tests, all single channel flow tests will be first conducted using nitrogen as the working fluid, with a Reynolds number based comparison made to the He/Xe working fluid for the full HPR-HX.

\section{Test Article Description}

The test article for the single module DDG flow test is shown in Figure 1. Nitrogen enters the test article at the lower end of the system, flows through a turbine flow meter, and into the test article. Two K-type thermocouples are located at both the entrance and the exit of the flow channel to assure that accurate temperature changes are measured. Although the thermocouples have been well secured at the inlet and exit of the flow channel, duplication of the temperature measurement should allow the experimenter to readily determine if any of the thermocouples has detached during operation, causing it to be out of the main flow stream or to be in contact with the metal housing. Using the inlet and outlet thermocouples, the temperature rise across the module can be determined and compared to the expected temperature increases in the actual core design. Similarly, pressure measurements are made at the channel entrance and exit, using Type 872 Flow-Through Micro-Baratron pressure transducer with a range of 0 $100 \mathrm{psi}$ (measurement accuracy of $\pm 1 \%$ of reading). Atmospheric pressure is also measured at the test article. Flow measurements were acquired using a turbine flow meter (model FT-12AENA-GEAS2), manufactured by Flow Technology, coupled with a frequency-to-DC converter (model SP741-V10-120-WM) manufactured by Sponsler Co., Inc. (measurement uncertainty of $\pm 0.11 \%$ ).

\section{DDG Coolant Flow Channel}

For the DDG system, the gas flow annulus is formed by the central fuel tube, which houses the resistance heater, and the outer stainless steel tube. Two flow channel designs were tested to determine the effect of changes in the flow annulus geometry on pressure drop: 1) The fuel tube was wrapped with a $0.0625 "(1.6 \mathrm{~mm})$ diameter wire to maintain a concentric location of the heater housing inside the outer tube. The wire spiraled with a three inch pitch along the full length of the tube, shown in Figure 2, and was welded at each of the ends to hold the wire in place. 2) Three sets of three wires were located around the circumference of the tube to provide concentric positioning, as shown in Figure 3. This design will be referred to as the "finned" design. Each 1.75 " $(44.5 \mathrm{~mm})$ length of wire in the set of three is located at 120 degree intervals around the circumference, and welded at each end to hold the wire in place.

In the series of tests that were conducted, the heater was held in place at the downstream end of the annulus either by a triangular orifice or by a metal plug, shown in Figure 4. The orifice and plug also provided a gas seal to prevent unwanted gas flow through the heater. Further, the orifice serves to provide a flow resistance in the channel, to reduce channel flow for a given pressure drop. Orifices will be used in the reactor to match the annulus flow to the known power in the fuel (which varies radially across the core) to provide a uniform coolant temperature rise in the coolant channels. Initial calculations indicated that the orifice would be a significant contributor to the pressure drop in the channel. For both channel designs, tests were conducted with the metal plug as well as the flow orifice, to be able to better quantify the channel flow performance exclusive of the orifice.

\section{DDG SINGLE CHANNEL RESULTS}

Initial testing indicated that prior to data acquisition, the resistance heater used in the test configuration must be "burned-in" to eliminate binding materials that were used in heater fabrication. During this time, higher 
temperatures and slightly lower pressure drops were observed than during subsequent heater operation. Heater operation at $1 \mathrm{~kW}$ for approximately one hour proved to be sufficient. Each data acquisition was for a minimum of two minutes, with data taken every ten seconds; hence, multiple data points were taken at each flow condition.

In each test, the goal was to maintain a constant outlet temperature of $202{ }^{\circ} \mathrm{C}$ assuming that the inlet temperature would remain constant throughout the test. Because it was difficult to maintain this precise temperature difference, the temperature rise along the flow channel varied slightly through the course of each test. In addition, it was noted that during the course of testing the inlet nitrogen temperature dropped from approximately $22{ }^{\circ} \mathrm{C}$ to a low of approximately $16^{\circ} \mathrm{C}$ at the end of testing due to the expansion of the nitrogen gas. Future tests will be conducted to maintain constant temperature rise along the flow channel rather than focusing on a specific outlet temperature. In each test, the heater was set to the power indicated in the corresponding test matrix, and the nitrogen flow rate was selected to achieve the desired outlet temperature. Test data were acquired from low power, low flow conditions to high power, high flow conditions.

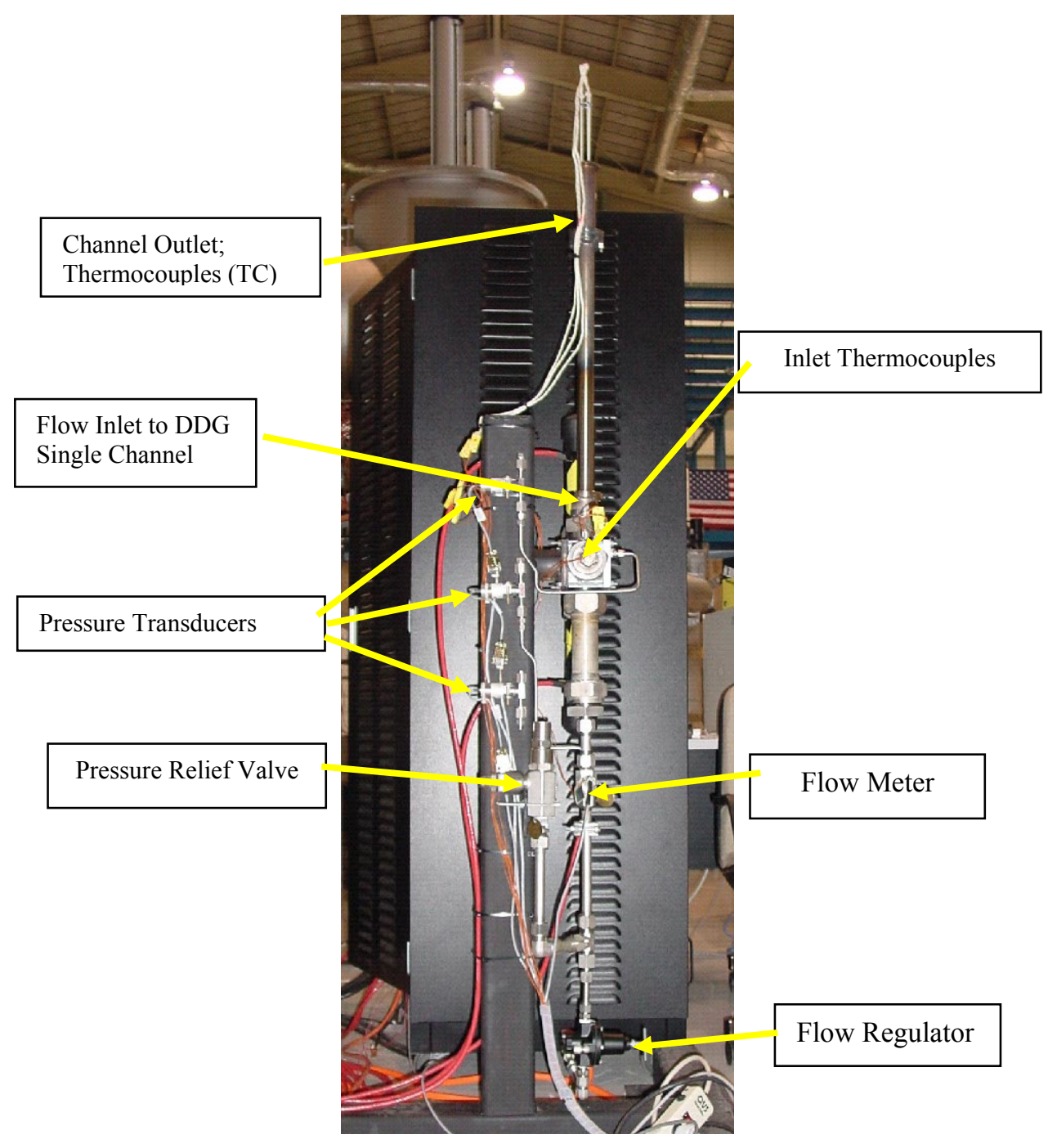

FIGURE 1. DDG Single Channel Test Apparatus. 


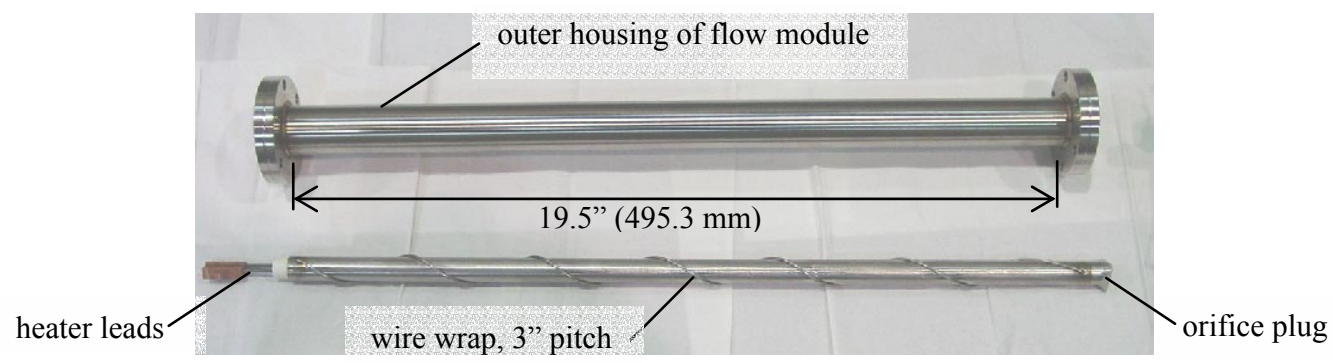

FIGURE 2. Breakout of Flow Path; Lower Configuration Fits Snugly Inside the Upper Tube Housing. (The spiral wire wrap shown here centers the heater in the outer housing and provides a snug fit for the heater configuration.)

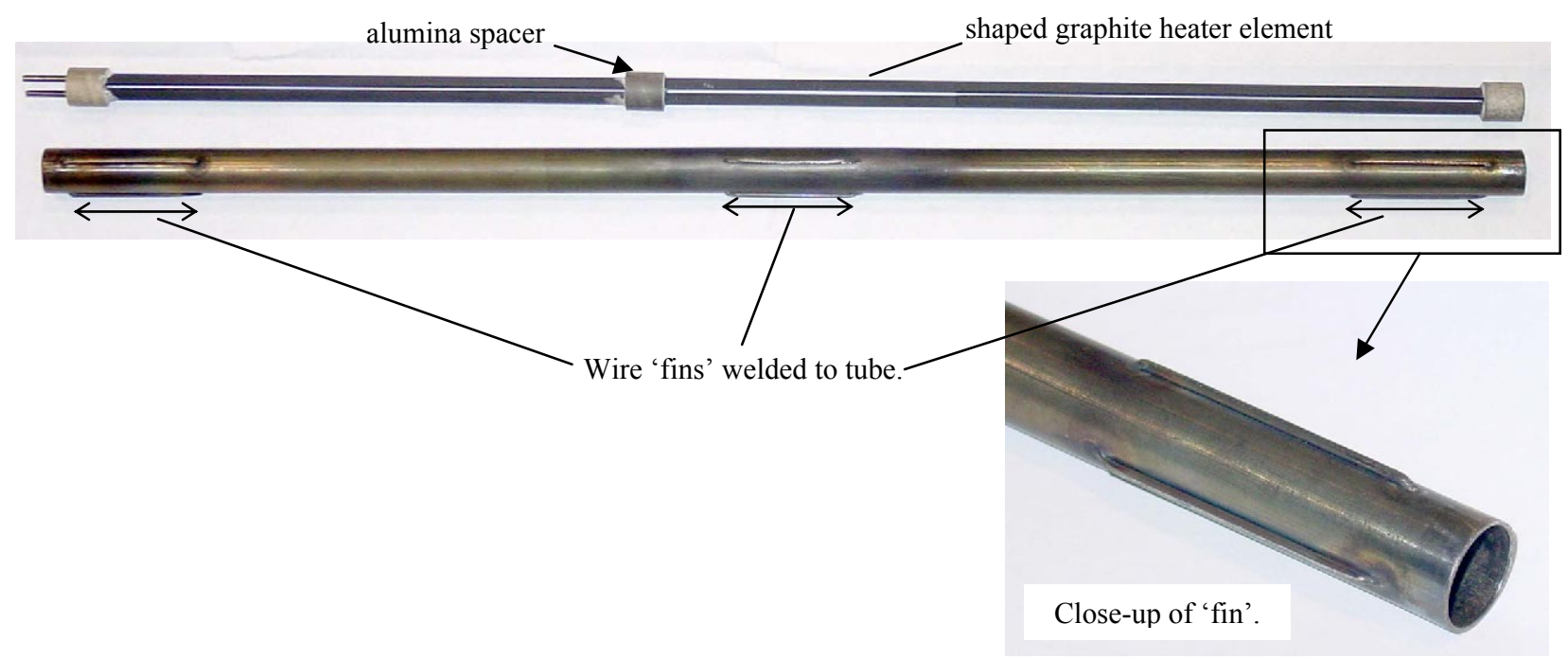

FIGURE 3. "Finned" Design for Maintaining Concentric Placement of the Heater Housing.

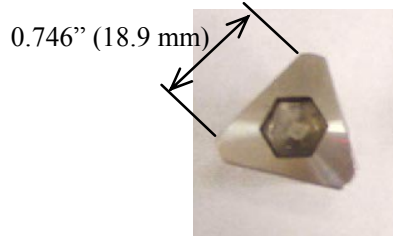

(a) Triangular Orifice Plug

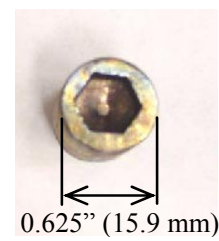

(b) Metal Plug (No Flow Constriction)

FIGURE 4. Orifice and Plug Designed to Hold Heater in Place at the Downstream End of the Flow Annulus with (a) Flow Constriction and (b) No Flow Constriction at the Outlet.

Figure 5 shows the measured and calculated pressure drops as a function of nitrogen flow rate. The error bars in this figure are based on measurement accuracies of $1 \%$ of the instrument reading for the pressure; the error in the flow rate is a compilation of the $0.11 \%$ uncertainty in the frequency to $\mathrm{DC}$ converter and the error in the pressure measurement (used to convert the measured actual cubic feet per minute (ACFM) to mass flow rate). One may note that the pressure drop appears to be constant for several different flow rates in each test. This phenomenon is generally in regions where the pressure drop curve has a small slope, in thus where small increases in the flow rate do not correspond to a large change in the pressure drop. This result is a function of the LabView data acquisition. 
The default setting in LabView is to update a measurement only if a value varies more that $1 \%$. This specification prevents the pressure data from being jumpy during data acquisition, but results in identical pressure drops for more than one power/flow rate combination. Future tests will eliminate this parameter from the data acquisition program so that small changes in the pressure drop will be measurable.

In addition, accuracy was limited by the available hardware at the time of the test. As discussed in the experimental design, the differential pressure data were acquired using two separate measurements of the absolute pressure, then reporting the pressure drop as the difference in these two readings. Measuring a pressure drop on the order of a few psi on a $0-100$ psi gauge with an accuracy of $1 \%$ of the reading is inadequate. More accurate measurements of the pressure drop are possible using a differential pressure gauge referenced to the pressure at the inlet of the flow channel. This hardware has been ordered and will be implemented in all subsequent tests.
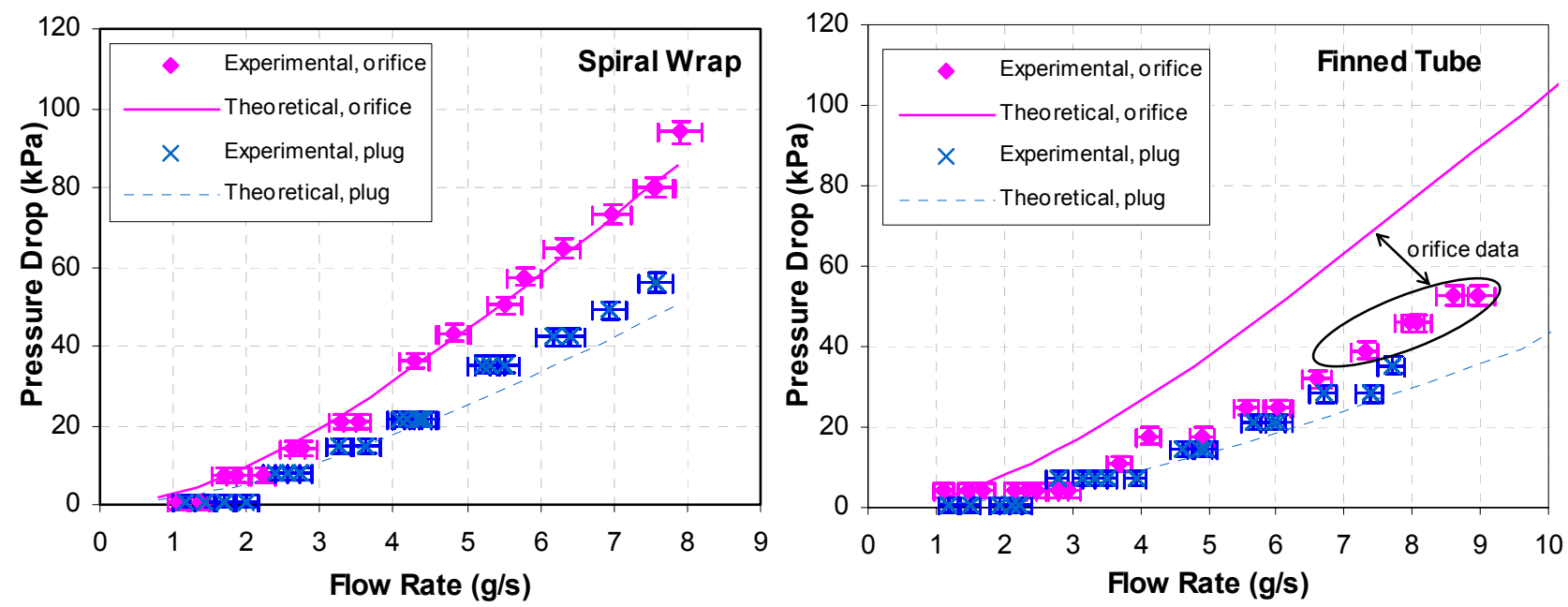

FIGURE 5. Comparison Pressure Drop along the Axial Direction of the DDG Coolant Flow Channel.

In Figure 5 it is evident that generally good agreement between the measured and calculated pressure drop was obtained, with the exception of the finned annulus with an orifice. The poor agreement for this case is likely due to poor positioning of the test module. Upon disassembling the test module after completion of this test, it was noted that the orifice sat slightly above the flow outlet rather than snugly in the annulus. As a consequence, the orifice plug no longer constricted the flow to the desired extent, and the flow characteristics would be expected to more closely resemble those in the non-orificed test. Better care will be taken in subsequent tests to assure proper positioning of the central tube and orifice to maintain the integrity of all experimental results.

General observations during testing indicated a more stable flow for the spiral wrapped flow annulus. However, the pressure drop in the spiral channel is significantly higher than for the finned annulus design, causing the finned design to be more desirable. During testing of the finned design, some chugging of the flow was audible. It is likely that the source of this chugging is the lack of insufficient back pressure in the annulus that results from testing at atmospheric pressure.

\section{CONCLUSIONS}

The test completed for the single channel design showed reasonably good agreement between the measured and calculated pressure drops. As expected, the majority of the pressure drop observed in the DDG single channel tests is due to the orifice rather than the flow channel annulus. Due to the smaller pressure drop present in the finned tube design, this configuration was selected for the full 37 pin DDG core testing. The single channel test configuration has been modified to run the DDG tests at an outlet pressure of $150 \mathrm{psi}(1.0 \mathrm{MPa})$, such that the results will better reflect the actual conditions in the full 37 pin design and eliminate potential complications with compressed flow. At this pressure, the calculated pressure drops along the annulus are significantly smaller than for atmospheric outlet 
pressure. A differential pressure gauge will be installed, which will allow for rapid, multiple differential pressure measurements and will greatly improve the measurement accuracy of the pressure drops. The multiple measurements will allow for detailed measurements of pressure drop along the flow channel.

\section{NOMENCLATURE}
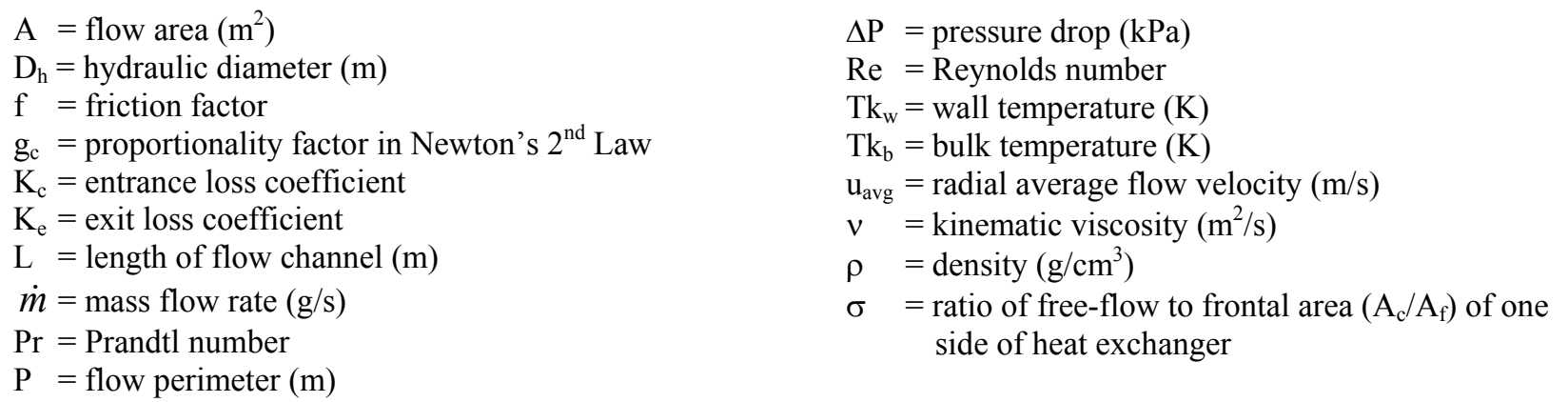

\section{ACKNOWLEDGMENTS}

This work was performed in collaboration with Los Alamos National Laboratory and the NASA Marshall Space Flight Center with funding provided by NASA Headquarters. NASA's Project Prometheus, the Nuclear Systems Program, supported the work described within this paper, in whole or part, as part of the program's technology development and evaluation activities. Any opinions expressed are those of the author(s) and do not necessarily reflect the views of Project Prometheus.

\section{REFERENCES}

Godfroy, T.J., Bragg-Sitton, S.M., and Van Dyke, M.K., "Thermally Simulated Testing of a Direct-Drive Gas-Cooled Nuclear Reactor," in proceedings of the International Congress on Advances in Nuclear Power Plants, Cordoba (ICAPP '03), Spain, May 4-7, 2003, Paper No. 3343.

Kapernick, R.J. and Guffee, R.M., "Thermal Stress Calculations for Heatpipe-Cooled Reactor Power Systems," in proceedings of Space Technology and Applications International Forum (STAIF-2003), edited by M. El-Genk, AIP Conference Proceedings 654, Melville, New York, 2003, pp. 457-465.

Kays and London, Compact Heat Exchangers, McGraw-Hill Companies, 1964.

Takase, K., "Forced Convective Heat Transfer in Square-Ribbed Coolant Channels with Helium Gas for Fusion Power Reactors," Fusion Engineering and Design 49-50, 349-354 (2000).

Wright, S.A. and Lipinski, R.J., "Pin-Type Gas-Cooled Reactor for Nuclear Electric Propulsion," in proceedings of Space Technology and Applications International Forum (STAIF-2003), edited by M. El-Genk, AIP Conference Proceedings 654, Melville, New York, 2003, pp. 408-419.

Wright, S.A., Lipinski, R.J., Godfroy, T.J., and Bragg-Sitton, S.M. "Direct-Drive Gas-Cooled Reactor Power System: Concept and Preliminary Testing," in proceedings of Space Technology and Applications International Forum (STAIF-2003), edited by M. El-Genk, AIP Conference Proceedings 654, New York, 2003, pp. 445-450.

Vandyke, M., Houts, M., Godfroy, T., Dickens, R., Poston, D., Kapernick, R., Reid, R., Salvail, P., and Ring, P., "Phase I Space Fission Propulsion System Testing and Development," in proceedings of Space Technology and Applications International Forum (STAIF-2002), edited by M. El-Genk, AIP Conference Proceedings 608, Melville, New York, 2002, pp. $692-697$. 